\title{
IMPLEMENTASI FUZZY C-MEANS UNTUK CLUSTERING MAHASISWA BERDASARKAN NILAI MASUK PERGURUAN TINGGI
}

\author{
Siti Mujilahwati ${ }^{1}$, Retno Wardhani ${ }^{2}$ \\ ${ }^{1,2}$ Teknik Informatika, Fakultas Teknik, Universitas Islam Lamongan \\ Jl. Veteran No.53 A Lamongan, Jawa Timur \\ E-mail:moedjee@gmail.com ${ }^{1}$,retzno@yahoo.com ${ }^{2}$
}

\begin{abstract}
ABSTRAKS
Penyaringan tes ujian pada penerimaan mahasiswa baru atau biasa disingkat dengan PMB, merupakan salah satu tahapan selain melengkapi berkas administratif. Pada Universitas Islam Lamongan (Unisla), tes penyaringan ini digunakan untuk melihat potensi calon mahasiswa berdasarkan nilai yang diperoleh. Dilihat dari hasil tes ini, maka langkah selanjutnya adalah panitia PMB dapat menentukan calon mahasiswa yang harus mengikuti kuliah matrikulasi atau tidak. Untuk saat ini penentuan dari hasil nilai tes dilakukan secara mengurutkan dari nilai tertinggi. Panitia juga akan memberikan nilai batas minimal dari nilai rata-rata tes yang diberikan untuk menentukan calon mahasiswa yang berhak tidak mengikuti kuliah matrikulasi. Pada penelitian ini akan membuat pengujian model klaster untuk menentukan kelompok calon mahasiswa yang tidak wajib mengikuti kuliah matrikulasi dan yang wajib mengikuti. Metode klaster yang digunakan adalah Fuzzy C-Means. Dengan menggunakan data uji sebanyak 400 data calon mahasiswa dan menggunakan 5 atribut nilai dari hasil tes PMB. Dan pengujian metode ini diimplementasikan pada Software Matlab telah mendapatkan hasil klaster 1 (Tidak Mengikuti kuliah matrikulasi) sebanyak 178 dengan nilai tes rata-rata 273,039 sedangkan pada klaster 2 (Wajib mengikuti kuliah matrikulasi) sebanyak 222 dengan nilai tes rata-rata 212,610.
\end{abstract}

\section{Kata Kunci - Fuzzy C-MEANS, Exam PMB, Clustering, Matlab}

\begin{abstract}
Screening of exam tests on new student admissions or commonly abbreviated as PMB, is one of the stages besides completing administrative files. At the Universitas Islam Lamongan (Unisla), this screening test is used to see the potential of prospective students based on the scores obtained. Judging from the results of this test, the next step is that the PMB committee can determine whether or not prospective students should attend the matriculation course. For now, the determination of the results of the test scores is carried out in order of the highest score. The committee will also provide a minimum value of the average test score given to determine which prospective students are eligible not to attend the matriculation course. This research will make a cluster model test to determine the group of prospective students who are not obliged to take matriculation courses and who are obliged to take part. The cluster method used is Fuzzy C-Means. By using test data as much as 400 prospective student data and using 5 attribute values from the PMB test results. And the testing of this method implemented in the Matlab Software has obtained 178 results for cluster 1 (not taking matriculation courses) with an average test score of 273.039 while in cluster 2 (compulsory attending matriculation courses) there are 222 with an average test score of 212.610.
\end{abstract}

\section{Keywords : Fuzzy C-MEANS, Exam PMB, Clustering, Matlab}

\section{PENDAHULUAN}

Calon mahasiswa baru dengan kuota lebih dari 1000 calon mahasiswa. Pendaftaran calon mahasiswa baru (PMB) pada kampus ini dilakukan dengan berbagai jalur, bisa dengan jalur prestasi, bidikmisi dan juga jalur regular. Selain melengkapi berkas administrasi seperti formulir dan kelengkapan lainnya, calon mahasiswa juga akan diberikan tes ujian bagi PMB. Tes ini meliputi Tes Potensi Akademik (TPA), Tes Bahasa Inggris (TOEFL), Tes Wawasan Kebangsaan (TWK), Tes Kemampuan Umum (TKU) dan Tes Keagamaan. Dari hasil tes tersebut yang nantinya akan menjadi syarat masuk calon mahasiswa baru. Yaitu dengan status lulus dengan mengikuti kuliah matrikulasi dan lulus tanpa mengikuti kuliah matrikulasi. Untuk saat ini panitia PMB masih menggunakan cara yang manual dan bersifat kira-kira saja. Yaitu mengurutkan hasil nilai dari terbesar ke terkecil, yang selanjutnya dari nilai tersebut akan disesuaikan dengan nilai batas minimal. Nilai batas minimal ini yang bersifat kira-kira. Dikarenakan disesuaikan dengan nilai tes ratarata. Jika nilai rata-rata atau grade saat tes bagus maka batas minimal akan diberikan nilai tinggi. Dan jika nilai tes rata-rata masuk grade rendah, maka nilai minimal juga rendah.

Dari analisi dilapangan ini maka, pada penelitian ini bertujuan memberikan solusi pengelompokkan dengan cara sistematis, cepat dan tepat. klaster merupakan group / kelompok. Pengklasteran berarti mengelompokkan. Pada teknik klaster hal pertama yang di utamakan adalah kemiripan data pada masing-masing anggota klaster. 
Selanjutnya adalah bahwa hasil klaster belum diketahui sebelumnya. Untuk itu teknik klaster ini memiliki beberapa metode untuk menyamakan atau menentukan kemiripan data untuk dijadikan menjadi satu kelompok/klaster. Yaitu bisa dengan menghitung jarak tiap masing-masing data. Untuk itu pada teknik klaster ini membutuhkan sebuah variabel input untuk dihitung nilai jaraknya. Ada beberapa konsep dasar untuk melakukan pengklasteran / pengelompokkan yaitu dengan cara sequential ( Hard Clustering, Fuzzy Clustering, Possibilistic Clustering) dan Hierarchical Cluster (Agglomerative, Divisive, Combinations).

Fuzzy Clustering merupakan salah satu teknik pengklasteran dengan cara menentukan sebuah klaster yang optimal dalam ruang vektor yang didasarkan pada bentuk normal ecludean (jarak) antar vektor. Fuzzy CMeans itu sendiri memiliki teknik, dimana setiap titik data merupakan anggota lebih dari satu klaster secara simultan, atau biasa disebut nilai derajat keanggotaan [1]. Konsep dari Fuzzy C-Means pertama yang dilakukan adalah menentukan pusat cluster yang akan dijadikan tanda lokasi rata-rata untuk tiap data pada klaster yang akan menjadi anggota pada klaster tersebut. Yang selanjutnya hasil klaster pertama belum tentu memiliki keakuratan pada anggota klasternya. Sehingga pada metode ini dilakukan perbaikan derajat keanggotaan secara berulang dengan mempertimbangkan nilai fungsi keanggotaan dan nilai tersebut menuju pada lokasi yang tepat [2].

Fuzzy C-Means merupakan salah satu metode yang sangat mudah dipahami dan metode ini dapat menghasilkan hasil klaster yang cukup baik. Sebagai contoh pada penelitian sebelum sebelumnya, dari tahun ke tahun sampai tahun terakhir ini metode ini masih banyk yang menggunakan sebagai lata bantu menentukan anggota-anggota kelompok tiap klaster. Diantaranya ada Aditya [3] melakukan pengujian dua metode yaitu metode K-means dan Fuzzy C-Means, pengujian ini bertujuan untuk membandingkan hasil uji performa validitas dan metode Fuzzy C-Means mendapatkan hasil lebih bagus yang hampir mendekati nilai 1 dibandingkan dengan metode K-Means. Pada tahun berikutnya penelitian dari Rio [4] melakukan pengujian dan berbandingan dua metode yaitu K-Means dengan Fuzzy C-Means untuk mengelompokkan tingkat kepuasan penonton televisi. Pada penelitiannya menunjukkan bahwa metode Fuzzy CMeans mampu menghasilkan keakurasian klaster yang lebih tepat dibandingkan dengan metode K-Means.

Masih banyak lagi penelitian yang melakukan pengujian metode Fuzzy C-Means [5] [6] [7] [8] hasil pengelompokkan yang diperoleh dari beberapa penelitian terdahulu membuktikan bahwa metode Fuzzy C-Means ini sangat cocok dan tepat digunakan untuk melakukan pengelompokkan atau klasterisasi secara baik. Oleh sebab itu sesuai dengan tujuan dari penelitian ini, bahwa implementasi metode Fuzzy C-Means akan mampu membantu mengelompokkan hasil ujian PMB.

\section{PEMBAHASAN}

\section{A. Analisis Data}

Tahap analisis data ini dilakukan dengan tujuan untuk mengetahui data nilai hasil tes yang diperoleh calon mahasiswa. Dan hasil yang diperoleh dari analisis data nilai tes PMB ini adalah data yang memiliki tipe numerik yaitu nilai dengan rentang $0-$ 800 dari seluruh tes. Setiap masing-masing tes memiliki grade nilai minimum dan maksimum. Nilai tersebut seperti digambarkan pada Tabel 1 berikut ini.

Tabel 1 Grade Nilai PMB

\begin{tabular}{|l|l|l|l|}
\hline No. & Jenis Tes & Minimal & Maksimal \\
\hline 1 & TPA & 200 & 800 \\
\hline 2 & TOEFL & 223 & 677 \\
\hline 3 & TWK & 75 & 100 \\
\hline 4 & TKU & 80 & 100 \\
\hline 5 & Keagamaan & 80 & 100 \\
\hline
\end{tabular}

Dari nilai yang diperoleh dan dilakukan analisis, data tes PMB dapat dilakukan pengelompokan secara sistematis dengan menggunakan konsep data mining. Algoritma yang dapat digunakan dengan prinsip cepat dan tepat adalah algoritma Fuzzy C-means. Supaya dapat diperoleh keanggotaan kelas matrikulasi dan tidak.

\section{B. Pengumpulan dan desain Data}

Berdasarkan hasil analisis data tes PMB bahwa data tes dapat digunakan konsep pengelompokkan atau clustering. Maka itu langkah selanjutnya adalah melakukan pengambilan atau pengumpulan data dari pihak panitia PMB. Berdasarkan proposal pengajuan pada penelitian ini data yang akan digunakan untuk pengelompokkan adalah 400 record. Maka dari 1.200 mahasiswa terdaftar maka kami ambil secara proposional dan acak di masing-masing fakultas dengan jumlah 400 record data. Adapun desain tabel yang akan dipakai untuk menampung dataset tersebut seperti pada Gambar 1 berikut ini.

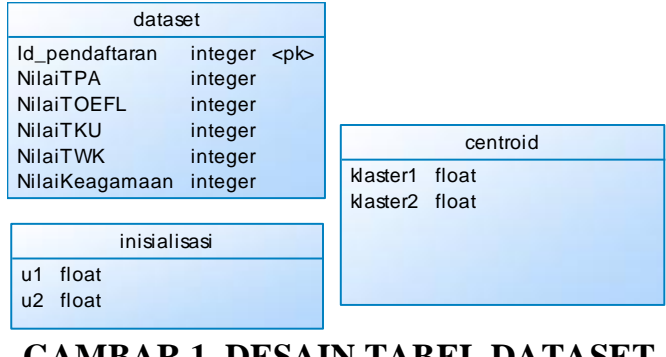

\section{GAMBAR 1. DESAIN TABEL DATASET}

Proses pengumpulan data ini dilakukan selama 2 hari kerja. dikarenakan ada beberapa prosedur yang harus dilakukan. termasuk pengajuan izin kepada pimpinan, baru hari berikutnya adalah menemui bagian server panitia pmb, untuk mengambil data nilai tes pmb. 


\section{Pengolahan Data}

Tahap Pengolahan data yang dilakukan pertama adalah memilih data secara random tiap masing-masing fakultas. Untuk memenuhi data 400 record. Data yang sudah dilakukan filtering dan juga perbaikan data noise selanjutnya kami lakukan fiksasi data.

Data fiks disebut dengan dataset. Dari dataset yang sudah siap akan disimpan difile CSV. Data yang dihasilkan pada tahap praproses dan akan digunakan adalah seperti pada Gambar 2 berikut.

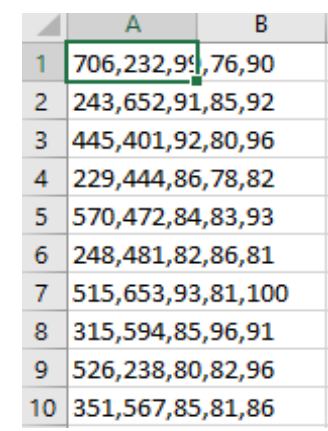

Gambar 2. Dataset Tes PMB CSV

Dengan menggunakan machine learning matlab maka dibutuhkan dataset bertipe .dat atau csv. Hasil data yang sudah dimodelkan tersebut langkah selanjutnya adalah akan dilakukan proses load dataset dan setting untuk implementasi metode Fuzzy C-Means. Dan selanjutnya dapat dilakukan proses clustering.

Perintah load data di matlab

dataPMB = csvread ('dataset-nonparameter.CSV') ;

\section{Melakukan Klaster}

Proses klaster akan dilakukan seperti pada tahapan proses Gambar 3 berikut ini.

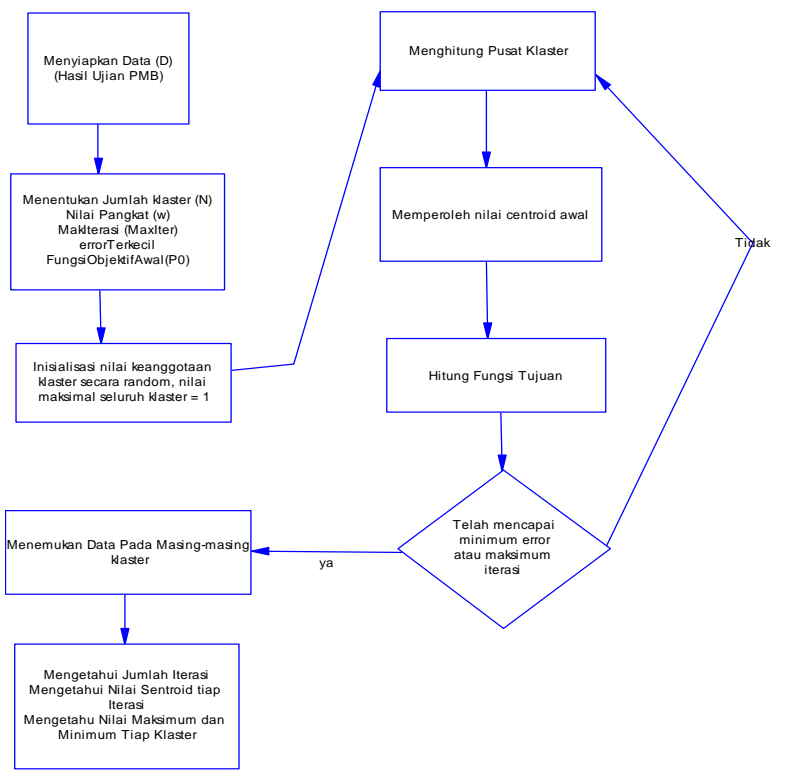

Gambar 3. Tahap Klaster dengan Fuzzy CMeans
Pada tahap ini akan dilakukan klasterisasi data tes PMB yang sudah disimpan sebagai dataset uji metode Fuzzy C-Means. Adapun algoritma dari metode Fuzzy C-Means ini adalah

1. Menentukan matrik DxN diaman D adalah banyak data yang akan digunakan $(\mathrm{D}=400)$, $\mathrm{N}$ adalah jumlah atribut/ variabel yang digunakan ( $\mathrm{N}=5$, Nilai TPA, Nilai TOEFL, Nilai TKU, Nilai TWK, Nilai Keagamaan)).

Tabel 2. Matrik DxN

\begin{tabular}{|l|l|l|l|l|l|}
\hline No & $\begin{array}{l}\text { Nilai } \\
\text { TPA }\end{array}$ & $\begin{array}{l}\text { Nilai } \\
\text { TOEFL }\end{array}$ & $\begin{array}{l}\text { Nilai } \\
\text { TKU }\end{array}$ & $\begin{array}{l}\text { Nilai } \\
\text { TWK }\end{array}$ & $\begin{array}{l}\text { Nilai } \\
\text { Keag } \\
\text { amaa } \\
\text { n }\end{array}$ \\
\hline 1 & 706 & 232 & 99 & 76 & 90 \\
\hline 2 & 243 & 652 & 91 & 85 & 92 \\
\hline 3 & 445 & 401 & 92 & 80 & 96 \\
\hline 4 & 229 & 444 & 86 & 78 & 82 \\
\hline 5 & 570 & 472 & 84 & 83 & 93 \\
\hline & $\cdot$ & $\cdot$ & $\cdot$ & $\cdot$ &. \\
$\cdot$ & $\cdot$ & $\cdot$ & $\cdot$ & $\cdot$ & $\cdot$ \\
$\cdot$ & $\cdot$ & $\cdot$ & $\cdot$ & $\cdot$ & $\cdot$ \\
\hline 400 & 393 & 346 & 86 & 83 & 90 \\
\hline
\end{tabular}

2. Menentukan banyak klaster $(\mathrm{c})=2$ (Mengikuti Matrikulasi, Tidak Mengikuti Matrikulasi)

Menentukan nilai Fuzzifier / Pangkat $(w)=2$ Memntukan nilai error terkecil $(\mathcal{E})=0.001$ Menentukan Fungsi Objektif Awal $\left(\mathrm{P}_{0}\right)=0$ Menentukan MakIterasi (MaxIter) $=100$

3.Inisialisasi matrik keanggotaan dengan nilai random maksimal nilai seluruh klaster $=1$, range antar klaster nilainya adalah (0-1). Menggunakan fungsi

$$
\sum_{i=1}^{e} \mu_{c i}=1
$$

4. Menghitung Pusat klaster dengan persamaan

$$
V_{c j}=\frac{\sum_{i=1}^{M}\left[\left(\mu_{i c}\right)^{W} \cdot X_{i j}\right)}{\sum_{i=1}^{M}\left(\mu_{i j}\right)^{W}}
$$

Pada kasus ini akan di hitung untuk 2 pusat klaster yaitu $V_{\text {ej }}$ Di mana c adalah klaster yang akan diberi nama (c1, c2). Dan $\mathrm{j}$ adalah atribut yang dipakai sebanyak 5 . Sehingga nilai $\mathrm{j}=1,2,3,4,5$.

Dari perhitungan Rumus 1, maka diperoleh matrik $\mathrm{V}$, yaitu matrik pusat klaster. 
Tabel 3. Matrik V (Pusat Klaster)

\begin{tabular}{|l|l|l|l|l|l|}
\hline \multirow{3}{*}{$\mathrm{V}=$} & $c_{1} j_{1}$ & $c_{1} j_{2}$ & $c_{1} j_{\mathrm{a}}$ & $c_{1} j_{4}$ & $c_{1} j_{5}$ \\
\cline { 2 - 6 } & $c_{2} j_{1}$ & $c_{2} j_{2}$ & $c_{2} j_{3}$ & $c_{2} j_{4}$ & $c_{2} j_{5}$ \\
\hline
\end{tabular}

5. Menghitung nilai Objektif dengan menggunakan persamaan 3

$$
P_{\mathrm{t}}=\sum_{i=1}^{\mathrm{n}} \sum_{k=1}^{e}\left(\left[\sum_{j=1}^{2}\left(X_{\mathrm{ij}}-V_{k j}\right)^{2}\right]\left(\mu_{i k}\right)^{2}\right)
$$

Dengan menggunakan data, $\mathrm{n}=400, \mathrm{c}=2$, diperoleh fungsi objektif sebesar $=$ Dari 32 iterasi yang diproses.

6. Menghitung perubahan matrik partisi menggunakan Persamaan 4 berikut.

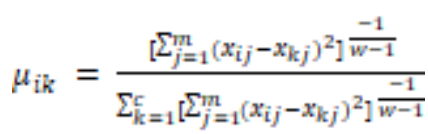

7. Cek Kondisi Berhenti
a. Jika
$\left(\left|P_{t}-P_{t-1}\right|<\varepsilon\right)$ atou $(t>$ Maxiter $)$ maka berhenti
b. Jika tidak : $\mathrm{t}=\mathrm{t}+1$, ulangi langkah ke 4 .

\section{HASIL DAN PEMBAHASAN}

\section{a. Gambaran Umum}

Data dari hasil tes ujian PMB di Unisla yang telah dikumpulkan dan dilakukan analisis data yang selanjutnya akan dipakai sebagai input data pada metode Fuzzy C-Means. Dalam implementasi dengan metode ini telah di tentukan beberapa parameter seperti Nilai Tes Potensi Akademik (TPA), TOEFL, TKU, TWK dan Tes Keagamaan.

Adapun jumlah cluster yang diterapkan adalah 2. Yaitu kelompok mengikuti kuliah matrikulasi dan kelompok tidak mengikuti matrikulasi. Berdasarkan [9]. bahwa yang biasa menentukan nilai fuzzifier awal (w) adalah 2. Dan dengan menggunakan nilai error terkecil 0,001 yang disebut juga dengan nilai epselon yang memiliki arti bahwa operasi iterasi akan berhenti jika nilai fungsi objektif terakhir kurang dari epselon. Adapun hasil yang diperoleh untuk menentukan matrik awal keanggotaan masingmasing klaster dengan nilai fuzzy atara (0-1) dengan menggunakan persamaan 1 .

Tabel 4. Matrik Keanggotaan

\begin{tabular}{|l|l|l|}
\hline $\begin{array}{l}\text { Random } \\
\text { Ke-i }\end{array}$ & $c_{i=1}$ & $c_{i=2}$ \\
\hline 1 & 0,757 & 0,243 \\
\hline 2 & 0,219 & 0,781 \\
\hline 3 & 0,199 & 0,801 \\
\hline 4 & 0,083 & 0,917 \\
\hline 5 & 0,897 & 0,103 \\
\hline
\end{tabular}

\begin{tabular}{|l|l|l|}
\hline$\cdot$ & $\cdot$ & $\cdot$ \\
$\cdot$ & $\cdot$ & $\cdot$ \\
$\cdot$ & $\cdot$ & $\cdot$ \\
\hline 400 & 0.132 & 0.868 \\
\hline
\end{tabular}

Berikutnya adalah hasil yang diperoleh untuk matrik / nilai pusat klaster dari 2 klaster dan juga 5 variabel. Dihitung dengan menggunakan persamaan 2.

Tabel 5. Pusat Klaster

\begin{tabular}{|l|l|l|l|l|}
\hline 641,761 & 455,550 & 89,588 & 87,949 & 90,348 \\
\hline 353,045 & 443,975 & 90,221 & 86,608 & 89,201 \\
\hline
\end{tabular}

Selanjutnya adalah mengitung nilai objektif $\left(\mathrm{P}_{\mathrm{t}}=\mathrm{P}_{1}\right)$ dengan menggunakan persamaan 3, diperoleh nilai sebesar 41464,46

Selanjutnya adalah hasil perhitungan perubahan matrik (U1) yang dihitung dengan menggunakan persamaan 4. Hasil matrik yang diperoleh ditampilkan seperti pada Tabel 6 berikut ini.

Tabel 6. Perubahan Matrik (U1)

\begin{tabular}{|l|l|l|}
\hline Data Ke-i & $c_{i=1}$ & $c_{i=2}$ \\
\hline 1 & 1,476 & 2,608 \\
\hline 2 & 2,696 & 1,427 \\
\hline 3 & 2,781 & 1,387 \\
\hline 4 & 3,840 & 1,158 \\
\hline 5 & 1,196 & 3,535 \\
\hline$\cdot$ & $\cdot$ & $\cdot$ \\
$\cdot$ & $\cdot$ & $\cdot$ \\
\hline & $\cdot$ & $\cdot$ \\
\hline 400 & 3,214 & 1,253 \\
\hline
\end{tabular}

Dari hasil perubahan matrik di atas, maka langkah terakhir adalah mengecek kondisi berhenti, dengan mengguunakan langkah ke 7 dari langkah metode Fuzzy C-MEANS yang telah dimodelkan $\varepsilon$ $=0,001$ dan hasil $P_{1}=41464,46$. Karena $P_{1}>\varepsilon$ maka proses selanjutnya adalah mengulang iterasi dimulai dari proses pencarian nilai pusat klaster (langkah ke 4). Seterusnya sampai di peroleh dimana kondisi 7 terpenuhi.

b. Pembahasan

Dengan menggunakan Matlab proses klaster mendapatkan 24 kali iterasi dengan nilai akhir nilai objektif $=0$ kondisi berhenti. Hasil dari matlab ditampilkan pada Gambar 4 berikut ini. 


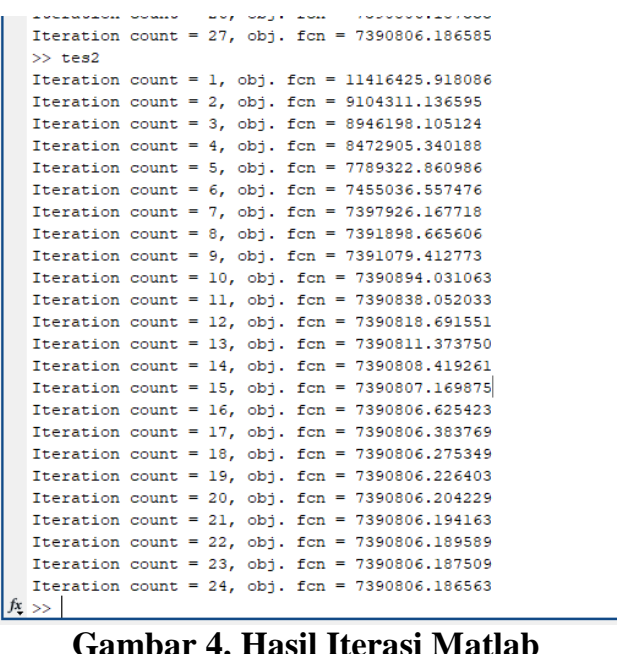

Gambar 4. Hasil Iterasi Matlab

Hasil Pembagian 2 klaster yang diperoleh dari matlab ditampilkan seperti pada Gambar 5 berikut. Kelompok 1 berwarna biru, merupakan kelompok calon mahasiswa yang tidak wajib mengikuti kuliah matrikulasi. Sedangkan kelompok gambar warna kuning adalah kelompok calon mahasiswa wajib mengikuti kuliah matrikulasi. Hasil dari pengelompokkan dari 400 calon mahasiswa tersebut dapat ditampilkan seperti pada Tabel 7 di bawah ini.

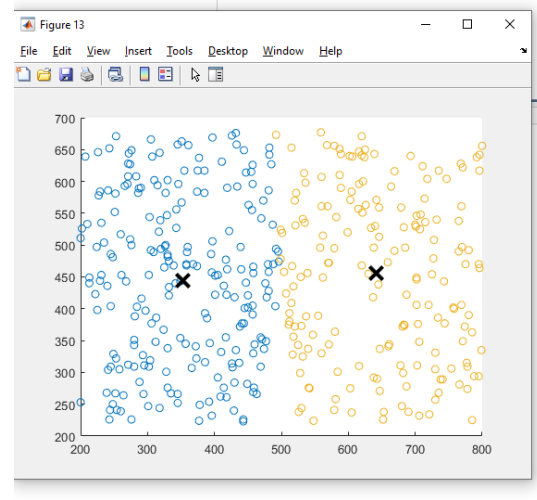

Tabel 7.

Hasil Clustering TesPMB

\begin{tabular}{|c|c|c|c|}
\hline \multirow[t]{2}{*}{ No. } & \multicolumn{2}{|c|}{$\begin{array}{l}\text { Derajat } \\
\text { Keanggotaan }\end{array}$} & \multirow[t]{2}{*}{ Klaster } \\
\hline & $\mathrm{C} 1$ & $\mathrm{C} 2$ & \\
\hline 1 & 1,476 & 2,608 & $\mathrm{C} 2$ \\
\hline 2 & 2,696 & 1,427 & $\mathrm{C} 1$ \\
\hline 3 & 2,781 & 1,387 & C1 \\
\hline 4 & 3,840 & 1,158 & C1 \\
\hline 5 & 1,196 & 3,535 & $\mathrm{C} 2$ \\
\hline 6 & 4,024 & 1,141 & C1 \\
\hline 7 & 1,881 & 2,119 & $\mathrm{C} 2$ \\
\hline 8 & 2,996 & 1,309 & $\mathrm{C} 1$ \\
\hline 9 & 1,913 & 2,087 & $\mathrm{C} 2$ \\
\hline 10 & 3,182 & 1,260 & $\mathrm{C} 1$ \\
\hline . & . & . & . \\
\hline . & . & & \\
\hline 400 & 3,214 & 1,253 & C1 \\
\hline \multicolumn{3}{|c|}{$\sum C 1$} & 178 \\
\hline & \multicolumn{2}{|c|}{$\sum C 2$} & 222 \\
\hline
\end{tabular}

Hasil analisis yang didapatkan dari pembagian 2 kelompok ini adalah untuk kelompok mahasiswa yang tidak wajib mengikuti kuliah matrikulasi memiliki nilai tes rata-rata 273,039, sebanyak 178 calon mahasiswa. Sedangkan untuk kelompok wajib mengikuti kuliah matrikulasi dengan nilai rata-rata 212,610 dengan jumlah calon mahasiswa sebanyak 222.

\section{KESIMPULAN}

Implementasi metode Fuzzy C-MEANS untuk pengelompokkan dari 400 data tes ujian PMB dengan menggunakan software matlab, dengan tujuan menentukan anggota pada klaster matrikulasi dan tidak. Dapat disimpulkan sebagai berikut :

1. Dari 400 data, dengan menggunakan target 2 klaster telah didapatkan hasil, bahwa 178 calon mahasiswa yang masuk pada klaster 1 (Tidak mengikuti matriikulasi) dengan nilai rata-rata 273,029. Sedangkan 222 dari calon mahasiswa masuk pada klaster 2 (wajib mengikuti matrikulasi) dengan nilai rata-rata hasil nilai ujian 212,610.

2. Dengan batasan grade nilai hasil ujian yang wajib diperoleh mahasiswa, maka sebaran anggota klaster hampir memiliki jarak yang cukup dekat. Sehingga hampir setengah dari data masuk pada klaster 1 dan 2 .

3. Dengan memanfaatkan teknik ini, maka penentuan kelompok mahasiswa yang wajib dan tidak mengikuti matrikulasi menjadi lebih tepat dan cepat di tentukan.

\section{PUSTAKA}

[1] S. P. H. KUSUMADEWI, Aplikasi Logika Fuzzy untuk Pendukung Keputusan, Yogjakarta: Graha Ilmu, 2004.

[2] D. I. V. H. M. RAHAKBAUW, "Implementasi Fuzzy C-Means Clustering dalam Penentuan Beasiswa," Barekeng (Jurnal Ilmu Matematika dan Terapan), pp. 1-11, 2017.

[3] E. Z. M. RAMADHAN A, "Perbandingan KMeans dan Fuzzy C-Means untuk pengelompokan Data User Knowledge Modeling," Seminar Nasional Teknologi Informasi, Komunikasi dan Industri (SNTIKI) 9, pp. 219-226, 2017.

[4] R. D. S. Y. MALIK A, "Perbandingan Algoritma K-Means Clustering dengan Fuzzy C-means dalam Mengukur Tingkat Kepuasan Terhadap Dakwah Surau TV," RABIT : Jurnal Teknologi dan Sistem Informasi Univrab, pp. 10-21, 2018. 
[5] R. R. I. P. A. RISMANTO, "Implementasi Fuzzy C-Means untuk Prediksi Perilaku Mahasiswa Berdasrkan Jumlah Ketidakhadiran," SMARTICS Journal, pp. 3946, 2017.

[6] N. S. N. A. F. DWITIYANTI, "Penerapan Fuzzy C-Means Cluster dalam pengelompokkan Provinsi Indonesia Menurut Indikator Kesejahteraan Rakyat," Faktor Exacta12, pp. 201-209, 2019.

[7] J. S. E. S. A. TAMAELA, "Cluster Analysis Menggunakan Algoritma Fuzzy C-means dan K-means Untuk Klasterisasi dan Pemetaan Lahan Pertanian di Minahasa Tenggara," Jurnal Buana Informatika, pp. 151-160, 2017.

[8] B. A. B. POERWANTO, "Implementasi Algoritma Fuzzy C-means dalam Mengelompokkan Kecamatan di Tana Luwu Berdasarkan Produktifitas Hasil Perkebunan," Jurnal MATRIK, pp. 163-172, 2019.

[9] P. E, Data mining mengolah data menjadi informasi menggunakan matlab, Yogyakarta: Andi Offset, 2014.

[10] B. S. D. Utomo, Perencanaan dan Pembangunan Sistem Informasi, Yogyakarta: Andi , 2002.

[11] V. Venkatesh, M. G. Morris, G. B. Davis and F. D. Davis, "User Acceptance of IT: Towards A Unified View," MIS Quarterly, pp. 425-478, 2003.

[12] I. G. N. Sedana and S. W. Wijaya, "UTAUT Model for Understanding Learning Management System," Internetworking Indonesia Jurnal Vol.2/No.2, pp. 27-32, 2010.

[13] R. Field, "Indonesia's Dangerous Haze," 26 October 2015. [Online]. Available: http://www.policyforum.net/indonesiasdangerous-haze/0.

[14] M. Syukur, 21 Oktober 2015. [Online]. Available:

http://news.liputan6.com/read/2345710/paruparu-penuh-asap-bocah-di-riau-meninggal. [Accessed 8 Oktober 2016].

[15] B. Warsito, D. Ispriyanti and H. Widayanti, "Clustering Data Pencemaran Udara Sektor Industri di Jawa Tengah Dengan Kohonen Neural Network," Jurnal PRESIPITASI, 2008.

[16] A. Iizuka, S. Shirato, A. Mizukoshi, M. Noguchi, A. Yamasaki and Y. Yanagisawa, "A
Cluster Analysis of Constant Ambient Air Monitoring Data from the Kanto Region of Japan," International Journal of Environmental Research and Public Health, pp. 6844-6855, 2014.

[17] J. Han and M. Kamber, Data Mining Concepts and Techniques Second Edition, San Francisco: Morgan Kaufmann, 2006.

[18] Asroni and R. Adrian, "Penerapan Metode Kmeans Untuk Clustering Mahasiswa Berdasarkan Nilai Akademik Dengan Weka Interface Studi Kasus Pada Jurusan Teknik Informatika UMM Magelang," Jurnal Ilmiah Semesta Teknika, pp. 76-82, 2015.

[19] E. PRASETYO, Data Mining Mengolah Data Menjadi Informasi Menggunakan Matlab, Yogjakarta: Andi Offset, 2014. 